\title{
First report of Epicoccum latusicollum causing root rot on Nicotiana tabacum in China
}

\author{
Xiaotong Gai ${ }^{1}$ - Ning Jiang ${ }^{1} \cdot$ Canhua $\mathrm{Lu}^{1} \cdot$ Zhenyuan Xia $^{1} \cdot$ Xiyun Qin ${ }^{1}$ \\ Received: 30 October 2019 / Accepted: 1 April 2020 / Published online: 26 May 2020 \\ (C) Società Italiana di Patologia Vegetale (S.I.Pa.V.) 2020
}

Keywords Epicoccum latusicollum · root rot · Nicotiana tabacum · disease

Tobacco is the important commercial crop in Yunnan province (China). In May 2019, a root rot disease was observed on $10-15 \%$ of tobacco plants in Dehong, Yunnan, China. The symptomatic plants that showed brown to black rot on tobacco shank and root were collected. The infected tissues from the symptomatic roots were incubated on PDA after surface sterilization at $25{ }^{\circ} \mathrm{C}$ for about 7 days. Three isolates were recovered from diseased plants and the morphological characteristics of the fungal isolates were studied. Fungal colonies on PDA were villiform and brownish; conidia ellipsoidal, aseptate, $(4.3 \pm 0.7 \times 2.4 \pm 0.5 \mu \mathrm{m})$, pycnidia brown $(128 \pm$ $40 \mu \mathrm{m})$. Isolated fungus was identified as Epicoccum species. The identity of isolate was confirmed by sequence analysis of rDNA-ITS, TUB, and RPB2 of strain HH12 (Accession Nos. MN622807, MN623288, and MN623287) using the primers ITS1/ITS4, Btub2Fd/Btub4Rd and RPB2-5F/RPB2-7cR, respectively (White et al. 1990; Woudenberg et al. 2009; Reeb et al. 2004). The resulting sequences were aligned with sequences retrived from GenBank and the resulting sequences shared $100 \%$ similarity with that of Epicoccum latusicollum (MH824373 and MH824403), while the RPB2 gene sequences were $99 \%$ identity to E. latusicollum Supplementary Fig. 1. Pathogenicity tests were conducted at $25{ }^{\circ} \mathrm{C}$ by inoculating fungus-containing PDA discs on the stems of five 45-day-old plants and three control plants inoculated with sterile PDA discs. Only the inoculated stems became brown necrotic after 5 days and showed typical brown

Electronic supplementary material The online version of this article (https://doi.org/10.1007/s42161-020-00548-9) contains supplementary material, which is available to authorized users.

Xiaotong Gai

gaixiaotong0617@126.com necrosis symptoms 10 days post inoculation Supplementary Fig. 2. The experiments were repeated three times and obtained similar results. Morpho-molecular identity of re-isolated fungus corresponded to E. latusicollum. To the best of our knowledge, this is the first report of E. latusicollum causing root rot on Nicotiana tabacum in China. The identification of E. latusicollumon on Nicotiana tabacum could provide relevant information for root rot prevention in tobacco leaf production.

Funding information Funding was provided by Yunnan Provincial Tobacco Monopoly Bureau (grant no. 2020530000241012).

\section{References}

Reeb V, Lutzoni F, Roux C (2004) Contribution of RPB2 to multilocus phylogenetic studies of the euascomycetes (Pezizomycotina, fungi) with special emphasis on the lichen-forming Acarosporaceae and evolution of polyspory. Molec Phylogenet Evoutionl 32:1036-1060

White TJ, Innis MA, Gelfand DH, Sninsky JJ (1990) PCR protocols: a guide to methods and applications. Academic Press, San Diego

Woudenberg JHC, Aveskamp MM, de Gruyter J, Spiers AG, Crous PW (2009) Multiple Didymella teleomorphs are linked to the Phoma clematidina morphotype. Persoonia 22:56-62

Publisher's note Springer Nature remains neutral with regard to jurisdictional claims in published maps and institutional affiliations. 